\title{
Significant non-linearity in nitrous oxide chamber data and its effect on calculated annual emissions
}

P. C. Stolk ${ }^{1,2}$, C. M. J. Jacobs ${ }^{2}$, E. J. Moors ${ }^{2}$, A. Hensen ${ }^{3}$, G. L. Velthof ${ }^{2}$, and P. Kabat ${ }^{1}$

${ }^{1}$ Earth System Science and Climate Change Group, Wageningen University, Wageningen, The Netherlands

${ }^{2}$ Alterra, Wageningen University and Research Centre Wageningen, The Netherlands

${ }^{3}$ Department of Air Quality and Climate Change, Energy research Centre of the Netherlands (ECN), Petten, The Netherlands

Received: 16 October 2008 - Accepted: 28 October 2008 - Published: 6 January 2009

Non-linearity in $\mathrm{N}_{2} \mathrm{O}$ chamber data affects annual emissions

P. C. Stolk et al.

Correspondence to: P. C. Stolk (petra.stolk@wur.nl)

Published by Copernicus Publications on behalf of the European Geosciences Union.

Title Page

Abstract

Introduction

Conclusions

References

Tables

Figures

14

$\rightarrow 1$

4

Back

Close

Printer-friendly Version

Interactive Discussion 


\section{Abstract}

Chambers are widely used to measure surface fluxes of nitrous oxide $\left(\mathrm{N}_{2} \mathrm{O}\right)$. Usually linear regression is used to calculate the fluxes from the chamber data. Non-linearity in the chamber data can result in an underestimation of the flux. Non-linear regression 5 models are available for these data, but are not commonly used. In this study we compared the fit of linear and non-linear regression models to determine significant non-linearity in the chamber data. We assessed the influence of this significant nonlinearity on the annual fluxes.

For a two year dataset from an automatic chamber we calculated the fluxes with linear and non-linear regression methods. Based on the fit of the methods $32 \%$ of the data was defined significant non-linear. Significant non-linearity was not recognized by the goodness of fit of the linear regression alone. Using non-linear regression for these data and linear regression for the rest, increases the annual flux with $21 \%$ to $53 \%$ compared to the flux determined from linear regression alone.

15 We suggest that differences this large are due to leakage through the soil. Macropores or a coarse textured soil can add to fast leakage from the chamber. Yet, also for chambers without leakage non-linearity in the chamber data is unavoidable, due to feedback from the increasing concentration in the chamber. To prevent a possibly small, but systematic underestimation of the flux, we recommend comparing the fit of a linear regression model with a non-linear regression model. The non-linear regression model should be used if the fit is significantly better. Open questions are how macropores affect chamber measurements and how optimization of chamber design can prevent this.

\section{Introduction}

25 Nitrous oxide $\left(\mathrm{N}_{2} \mathrm{O}\right)$ is one of the main contributors to the greenhouse effect causing global warming (Denman et al., 2007). Increasing $\mathrm{N}_{2} \mathrm{O}$ emissions therefore are of envi-
BGD

$6,115-141,2009$

\section{Non-linearity in $\mathrm{N}_{2} \mathrm{O}$ chamber data affects annual emissions}

P. C. Stolk et al.

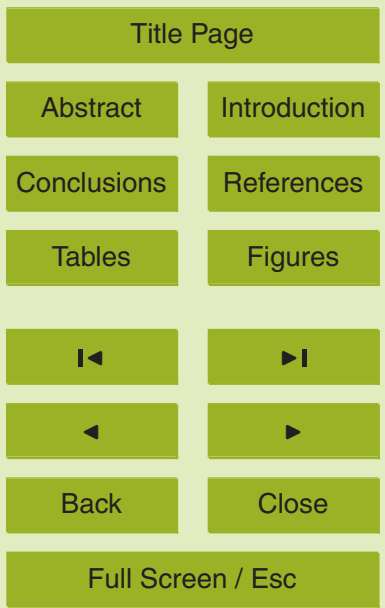

Printer-friendly Version

Interactive Discussion 
ronmental concern (IPCC, 2007), moreover because they affect atmospheric chemistry (Crutzen, 1981). Globally, soils are the major source of $\mathrm{N}_{2} \mathrm{O}$ emissions and arable land is the largest anthropogenic source (Denman et al., 2007). In Europe annual emissions are reported for grassland up to $28 \mathrm{~kg} \mathrm{~N}_{2} \mathrm{O}-\mathrm{Nha}^{-1}$ (Dobbie and Smith, 2003), 5 for arable land up to $17 \mathrm{~kg} \mathrm{~N}_{2} \mathrm{O}-\mathrm{N} \mathrm{ha}^{-1}$ (Jungkunst et al., 2006). Emissions will continue to rise with increasing world population and agricultural production (IPCC, 2000).

Chamber methods are widely used to measure $\mathrm{N}_{2} \mathrm{O}$ fluxes, especially non-flowthrough, non-steady-state (NFT NSS) chambers (Rochette and Eriksen-Hamel, 2008). The fluxes derived from the chamber data have been used for comparison studies, 10 e.g. to compare the impact of various agricultural management practices on the fluxes. Furthermore, these data have been used to calculate annual emissions for national inventories (IPCC, 2006), and to calibrate detailed process models (Del Grosso et al., 2000; Li et al., 1992; Riedo et al., 1998). Chamber data consist of concentration measurements in the headspace of the chamber over time; the flux is derived from the 15 concentration change over time. Usually, this change is assumed to be linear in time and the flux is determined with linear regression. However, already from the introduction of NFT NSS chamber methodology non-linear, decreasing concentration changes in the chamber headspace have been reported (Denmead, 1979). Use of linear regression will in these cases lead to an underestimation of the flux. This might not be

20 a problem for comparison studies, which use the fluxes relative to each other. For national inventories and modeling though, the absolute values are of interest and an underestimation in the absolute value of the flux would result in biased errors in these studies (Rochette and Eriksen-Hamel, 2008).

Exponential (Matthias et al., 1978) or quadratic (Wagner et al., 1997) regression 25 models have a better fit on non-linear chamber data than the linear regression model (Kroon et al., 2008; Hutchinson and Mosier, 1981). The non-linear regression models give higher flux estimates for these data: differences are reported up to $127 \%$ (Pedersen, 1999, 2000; Hutchinson et al., 1993; Kroon et al., 2008; Hutchinson and Mosier, 1981). To obtain a reliable flux, a linear regression model can only be used when

\section{BGD}

$6,115-141,2009$

\section{Non-linearity in $\mathrm{N}_{2} \mathrm{O}$ chamber data affects annual emissions}

P. C. Stolk et al.

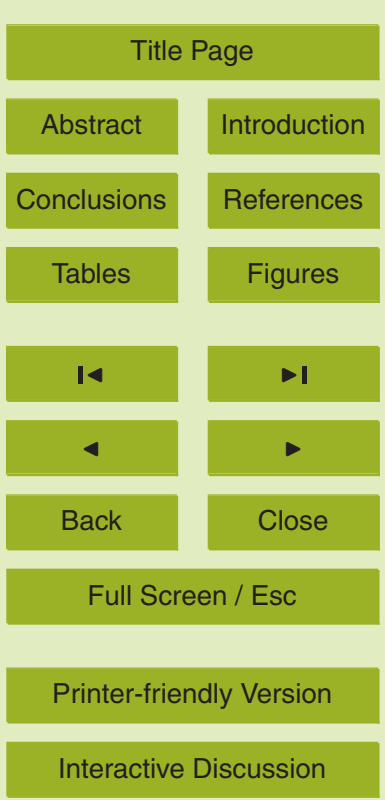


the non-linearity in the chamber data is not significant (Rochette and Eriksen-Hamel, 2008). However, there is no common practice to define this significance. The best way would be to compare the fit of linear and non-linear regression models. Examples in literature include comparison of the coefficient of determination and the adjusted 5 coefficient of determination (Kutzbach et al., 2007), comparison of chi-square (Kroon et al., 2008), calculation of the significance of the non-linear term in the regression model (Wagner et al., 1997), or simply looking at the shape of the concentration-time curve (Anthony et al., 1995). More commonly only the fit of the linear regression model is verified, using the coefficient of determination $r^{2}$ (e.g. Yamulki and Jarvis, 1999; 10 Velthof and Oenema, 1995; Breuer et al., 2000; Matthias et al., 1980). There are two problems associated with this method. Firstly, not only non-linear behaviour but also random measurement inaccuracies lower $r^{2}$. The influence of measurement inaccuracies is larger for small fluxes than for large fluxes. Therefore a lower $r^{2}$ is accepted for smaller fluxes than for larger fluxes and no overall lower limit for $r^{2}$ can be defined as criterion for acceptance of the linear regression model (e.g. Yamulki and Jarvis, 1999; Velthof and Oenema, 1995). Secondly, even for concentration data with a high $r^{2}$ for the linear regression, the underestimation of the flux determined with linear regression can be considerable. Modeling studies have demonstrated that there can still be a difference up to $16 \%$, even for data with $r^{2}>0.99$ (Conen and Smith, 2000; Pedersen et al., 2001). Thus, the question is how to determine if non-linearity in the concentration change in the chamber over time is significant and if a non-linear regression method should be used.

In this study we use two years of automatic chamber data for nitrous oxide from intensively managed grassland on clay. For this dataset, our aim is to:

- quantify the differences between the $\mathrm{N}_{2} \mathrm{O}$ fluxes derived from chamber data with linear and non-linear regression;

- evaluate how the goodness of fit of the regressions can be used as indicator for significant non-linearity in the chamber data;

\section{BGD}

$6,115-141,2009$

\section{Non-linearity in $\mathrm{N}_{2} \mathrm{O}$ chamber data affects annual emissions}

P. C. Stolk et al.

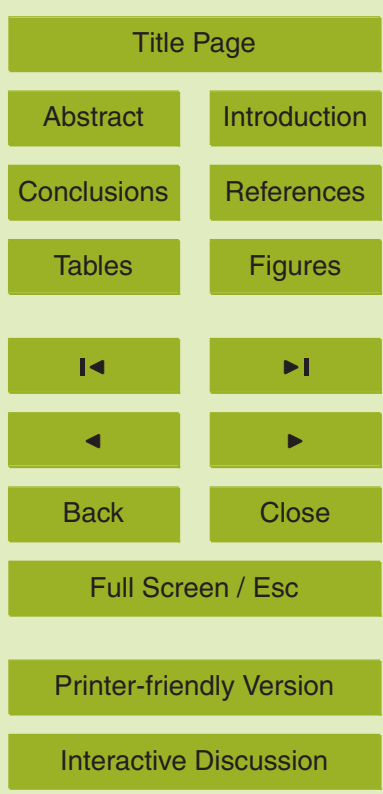


- assess the impact of significant non-linearity on the daily and annual $\mathrm{N}_{2} \mathrm{O}$ fluxes.

Throughout this paper, fluxes derived with linear, quadratic and exponential regression are referred to as linear, quadratic and exponential fluxes, respectively. Chamber data refers to the concentrations measured in the chamber during each closure period. In5 stantaneous fluxes refer to fluxes derived from one closure period of the chamber; daily and annual fluxes are calculated from these fluxes.

\section{Materials and methods}

\subsection{Site and data}

The $\mathrm{N}_{2} \mathrm{O}$ flux chamber data used in this study were collected in the context of the EU

GREENGRASS project (Soussana et al., 2007; Flechard et al., 2007) from 14 July 2002 to 13 July 2004 on grassland on clay soil near Lelystad in the Netherlands. Nitrogen was added as fertilizer and slurry and through grazing; average annual nitrogen addition was $286 \mathrm{~kg} \mathrm{~N} \mathrm{ha}^{-1}$. The grass was harvested two to four times a year.

The automatic chamber system had one non-insulated chamber with a size of $150.7 \mathrm{~m} \times 0.7 \mathrm{~m}$ and a height of $0.3 \mathrm{~m}$. The air inside the chamber was mixed continuously by a fan. This chamber alternated between two positions where an aluminium base was inserted $0.05 \mathrm{~m}$ in the soil. Gas concentration measurements inside the chamber were performed with a gas chromatograph (GC; Interscience Compact GC, The Netherlands) located in a cabin approximately $15 \mathrm{~m}$ North-East of the automatic chamber (with prevailing West-Southwest wind directions). $\mathrm{N}_{2} \mathrm{O}$ was measured using a $1 / 8^{\prime \prime}$ Molsieve $5 \mathrm{~A}$ column with a length of $2 \mathrm{~m}$. The temperature of the column oven was $50^{\circ} \mathrm{C}$ and the flow rate of the carrier gas $\left(\mathrm{N}_{2}\right)$ was $20 \mathrm{ml} \mathrm{min}^{-1}$. The GC was fitted with an electron capture detector (ECD) for $\mathrm{N}_{2} \mathrm{O}$. Measurement accuracy of the GC-ECD was $\sim 0.5 \mathrm{ppb}$, corresponding with a flux accuracy of $0.2 \mathrm{~g} \mathrm{~N}_{2} \mathrm{O}-\mathrm{Nha}^{-1} \mathrm{~d}^{-1}$.

Gas concentrations were determined at $0,5,15$ and $25 \mathrm{~min}$ after closing the box. High and low calibration standards were applied to the GC at 10 and 20 min after

BGD

6, 115-141, 2009

Non-linearity in $\mathrm{N}_{2} \mathrm{O}$ chamber data affects annual emissions

P. C. Stolk et al.

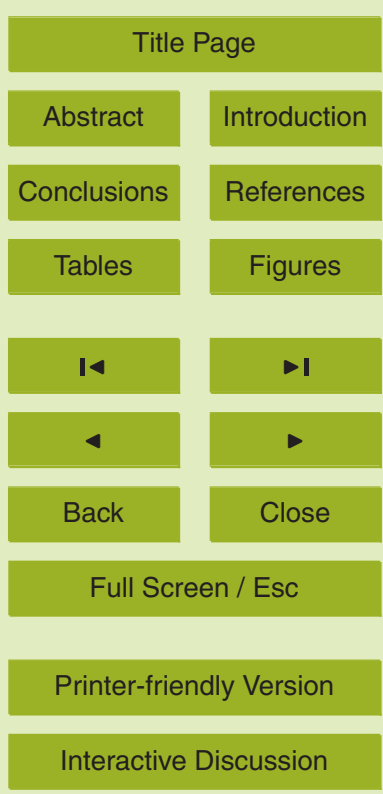


closing the chamber. The system measured for $30 \mathrm{~min}$ with the chamber in the first position (A), then another $30 \mathrm{~min}$ with the chamber in the second position (B). A third interval of $30 \mathrm{~min}$ was used to measure the ambient air concentration at different measurement heights, during which interval the chamber remained in position $\mathrm{B}$. In this way 5 chamber data for each position were obtained every $1.5 \mathrm{~h}$. Instrument failure resulted in some longer periods with missing data.

Chamber data ( $n=14167)$ was accepted if all measured concentrations were above $250 \mathrm{ppb}$, if the begin concentration was below $600 \mathrm{ppb}$, if the measured concentrations of the reference gases were within an acceptable range and if the concentration 10 changes over time were consistently positive or negative, taking into account the measurement accuracy. For chamber data with a standard deviation smaller than $2 \mathrm{ppb}$, the flux was assumed to be zero. Of the chamber data $25 \%$ was accepted $(n=3549)$, of which $6 \%$ was set to zero; $23 \%$ was discarded because of errors in the measured concentrations, and $52 \%$ was discarded because of inconsistent concentration changes. 15 Mainly data with small concentration changes (i.e. small fluxes) were discarded. In Fig. 1 some typical examples are depicted.

\subsection{Regression methods}

From the accepted chamber data the flux $F\left(\mathrm{~g} \mathrm{~N}_{2} \mathrm{O}-\mathrm{N} \mathrm{ha}^{-1} \mathrm{~d}^{-1}\right)$ was calculated by $F=h \cdot \frac{d C}{d t}{ }_{t=0} \cdot \frac{M_{m}}{V_{m}} \cdot f$

20 in which $h(\mathrm{~m})$ is de height of the chamber, $d C / d t_{t=0}\left(\mathrm{ppb} \mathrm{N}_{2} \mathrm{O} \mathrm{min}{ }^{-1}\right)$ is the concentration change at time $t=0, M_{m}\left(\mathrm{~g} \mathrm{~mol}^{-1}\right)$ molar weight of nitrogen and $V_{m}\left(\mathrm{~m}^{3} \mathrm{~mol}^{-1}\right)$ molar volume, calculated based on air temperature and pressure. The factor $f$ converts the fluxes from $\mathrm{ng} \mathrm{N} \mathrm{O} \mathrm{m}^{2} \mathrm{~min}^{-1}$ to $\mathrm{g} \mathrm{N}_{2} \mathrm{O}-\mathrm{N} \mathrm{ha}^{-1} \mathrm{~d}^{-1}$. The term $d C / d t_{t=0}$ was derived with linear, quadratic or exponential regression. All regressions were performed using MATLAB (MathWorks Inc., 2005, version 7.1.0.246). Linear regression on the chamber data was performed using the function polyfit, exponential regression with constraints

\section{BGD}

6, 115-141, 2009

\section{Non-linearity in $\mathrm{N}_{2} \mathrm{O}$ chamber data affects annual emissions}

P. C. Stolk et al.

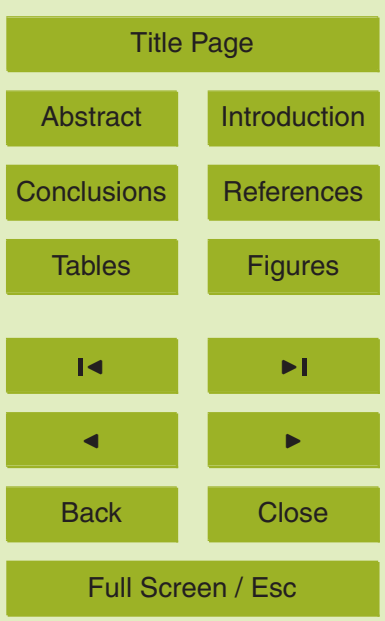

Printer-friendly Version

Interactive Discussion 
using the function Isqcurvefit and quadratic regression with constraints using the function fmincon.

For linear regression, the model fitted to the chamber data is given by

$$
C_{t}=a_{0}+a_{1} \cdot t
$$

5 in which $C_{t}(\mathrm{ppb})$ is the measured concentration at time $t, a_{0}(\mathrm{ppb})$ and $a_{1}\left(\mathrm{ppb} \mathrm{min}^{-1}\right)$ are regression parameters. In this case, $d C / d t_{t=0}$ is equal to $a_{1}$.

For quadratic regression, the model fitted to the chamber data is given by

$C_{t}=b_{0}+b_{1} \cdot t+b_{2} \cdot t^{2}$

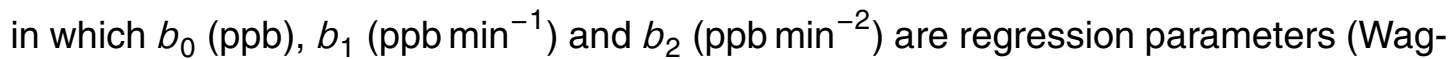
10 ner et al., 1997). Now, $d C / d t_{t=0}$ is equal to parameter $b_{1}$. Parameter $b_{0}$ represents the concentration at $t=0$ and $b_{2} \cdot t^{2}$ can be regarded an extra loss term as compared to the linear regression (Wagner et al., 1997). The graph of a quadratic equation can take a parabolic shape, with a minimum or maximum and a change in sign of the slope. One of the assumptions we made is that $d C / d t$ is consistently positive or negative. To 15 make certain that $d C / d t$ does not change sign during the closure period of $25 \mathrm{~min}$, the quadratic regression was applied with the following constraint:

$\frac{d C}{d t}{ }_{t=0} / \frac{d C}{d t}_{t=25}>0$

For exponential regression, a model based on Fick's law is fitted to the chamber data:

$c_{t}=c_{\max }-\left(c_{\max }-c_{0}\right) \cdot \exp (-k \cdot t)$

20 in which $c_{\max }(\mathrm{ppb}), c_{0}(\mathrm{ppb})$ and $k\left(\mathrm{~min}^{-1}\right)$ are regression parameters (de Mello and Hines, 1994; Matthias et al., 1978). Regression parameter $c_{0}$ represents the concentration at time $t=0$, regression parameter $c_{\max }$ the maximum concentration that can be

BGD

6, 115-141, 2009

Non-linearity in $\mathrm{N}_{2} \mathrm{O}$ chamber data affects annual emissions

P. C. Stolk et al.

Title Page

Abstract

Introduction

Conclusions

References

Tables

Figures

14

$\rightarrow 1$

4

Back

Close

Full Screen / Esc

Printer-friendly Version

Interactive Discussion 
reached in the chamber and $k$ a rate constant. In this case, the concentration change at time $t=0$ is given by

\section{BGD}

$$
\frac{d C}{d t}_{t=0}=\left(c_{\max }-c_{0}\right) \cdot k
$$

\subsection{Goodness of fit}

5 The goodness of fit for each regression was determined by the sum of squared errors SSE, the coefficient of determination $r^{2}$ and the adjusted coefficient of determination $r_{a}^{2}$ (Neter et al., 1996):

$$
\text { SSE }=\sum\left(\hat{C}_{t}-C_{t}\right)^{2}
$$

$r^{2}=1-\frac{\text { SSE }}{\sum\left(C_{t}-\overline{C_{t}}\right)^{2}}$

${ }_{10} r_{a}^{2}=1-\left(\frac{n-1}{n-p}\right) \frac{\mathrm{SSE}}{\sum}\left(C_{t}-\overline{C_{t}}\right)^{2}$

where $n$ is the number of observed concentrations $(n=4), p$ is the number of regression parameters, $C_{t}$ is the observed and $\hat{C}_{t}$ the modeled concentration. For the fluxes and each goodness-of-fit measure the median values were determined.

The goodness-of-fit of the regression methods has to be compared to decide whether 15 linear or non-linear regression should be used. In this comparison the different number of regression parameters of the linear and non-linear regression methods has to be taken into account, as is the case in $r_{a}^{2}$. Therefore data is defined as significantly nonlinear if $r_{a}^{2}$ of the non-linear regression methods is larger than $r_{a}^{2}$ of the linear regression method.

\section{Non-linearity in $\mathrm{N}_{2} \mathrm{O}$ chamber data affects annual emissions}

P. C. Stolk et al.

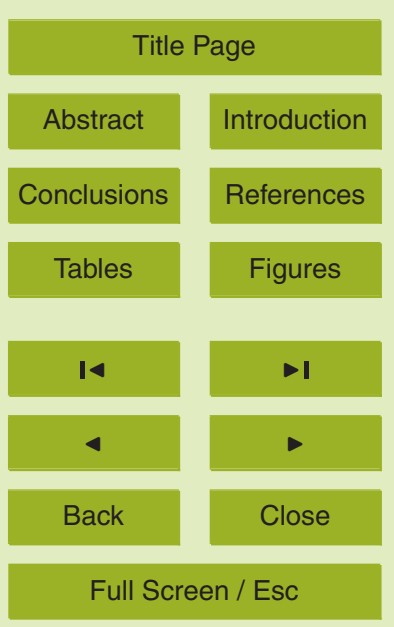

Printer-friendly Version

Interactive Discussion 
Daily fluxes were defined as the daily mean of the fluxes from positions $A$ and $B$ together; 416 daily fluxes could be calculated. Annual fluxes were calculated as the cumulative flux over 365 days and were determined for four partly overlapping peri-

ods starting at 25 July 2002, 7 November 2002, 20 February 2003 and 5 June 2003. For this purpose missing values in the time series of daily fluxes had to be estimated. Simple linear interpolation was not suited, because of larger gaps in the data (up to 33 days). The uncertainty in cumulative fluxes increases sharply with linear interpolation of gaps larger than seven days (Smith and Dobbie, 2001; Weitz et al., 1999;

\section{Results and discussion}

\subsection{Fluxes}

Figure 2 shows the calculated linear fluxes and the complete time series of daily linear fluxes after gap-filling. The graph illustrates the specific temporal behavior of $\mathrm{N}_{2} \mathrm{O}$ fluxes with background levels around zero and a few strong emission peaks. These peaks occured during the three summer periods, following fertilizer application and precipitation (not shown). It also shows the large gaps in the dataset that are mainly due to instrument failure.

In Fig. 3 the quadratic and exponential fluxes are plotted against their linear counterparts. In general, the linear fluxes are smallest and the exponential fluxes are largest, which is also evident from the median flux of the three regression methods (Table 1).
BGD

$6,115-141,2009$

\section{Non-linearity in $\mathrm{N}_{2} \mathrm{O}$ chamber data affects annual emissions}

P. C. Stolk et al.

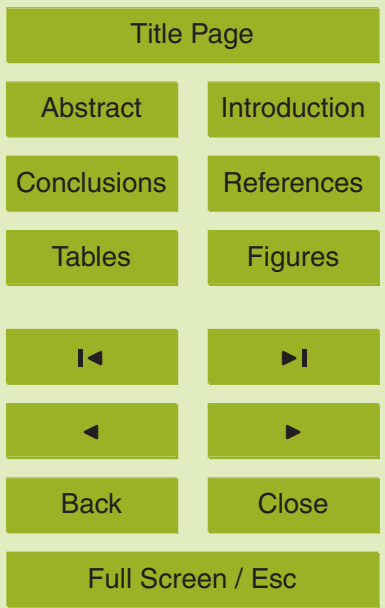

Printer-friendly Version

Interactive Discussion 
According to Fig. 3 for the instantaneous fluxes the difference between the linear fluxes and the quadratic and exponential fluxes is $59 \%$ and $162 \%$, respectively. Similar studies in literature found average differences ranging from $30 \%$ to $127 \%$ for instantaneous fluxes (Anthony et al., 1995; Pedersen, 2000; Kroon et al., 2008). The average dif5 ference found for the quadratic regression method is within this range, the average difference found for the exponential regression method is above this range.

\subsection{Goodness of fit}

In Table 1 the goodness of fit of the three regression methods is presented as the median value of SSE, $r^{2}$ and $r_{a}^{2}$. In general, for the exponential regression method the median for SSE is smallest and the median values for $r^{2}$ and $r_{a}^{2}$ are largest; this indicates that in general the exponential regression method has the best fit. The median for SSE and $r^{2}$ for the linear and quadratic regression method suggest that in general the quadratic regression has a better fit than the linear regression method. However, the median of $r_{a}^{2}$ is larger for the linear than for the quadratic regression method. This shows that the general better fit of the quadratic regression method is no more than has to be expected by the addition of an extra regression parameter.

Although the general fit of the exponential regression method is very good, the reliability of the result of the exponential regression is questionable. As the method is based on physical principles, the regression parameters should also stay within a physical acceptable range. The parameter $k$ has a physical interpretation (Hutchison and Mosier, 1981; Matthias et al., 1978):

$k=\frac{D_{p}}{d} \cdot \frac{1}{h}$

in which $D_{p}\left(\mathrm{~m}^{2} \mathrm{~min}^{-1}\right)$ is the actual diffusion coefficient of $\mathrm{N}_{2} \mathrm{O}$ in soil, $d(\mathrm{~m})$ is the depth of a plane with a constant concentration, and $h(\mathrm{~m})$ is the chamber height. The minimum value for $k$ is zero. Setting the soil diffusion coefficient equal to the diffusion coefficient in free air (Pritchard and Currie, 1982) a conservative estimate of the

BGD

$6,115-141,2009$

\section{Non-linearity in $\mathrm{N}_{2} \mathrm{O}$ chamber data affects annual emissions}

P. C. Stolk et al.

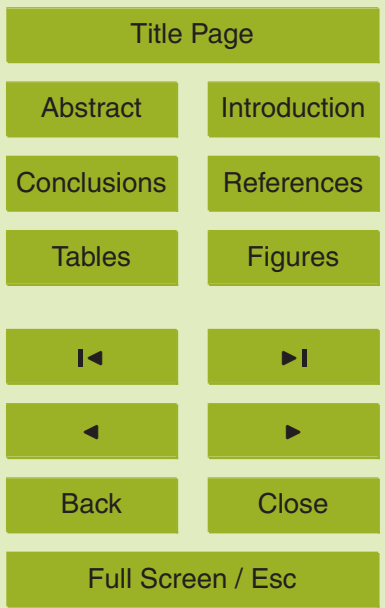

Printer-friendly Version

Interactive Discussion 
physical maximum for $k$ is given:

$k=\frac{8.58 \times 10^{-4}}{0.01} \cdot \frac{1}{0.3}=0.286 \mathrm{~min}^{-1}$

BGD

$6,115-141,2009$

For a significant part of the data (8\%) the regression result gives a $k$ above this value. In Fig. 4 the regression parameter $k$ is plotted against the relative difference 5 between the linear and exponential flux. It shows that the difference between the linear and exponential flux is directly related to the value of $k$. The maximum difference $\left(k=0.286 \mathrm{~min}^{-1}\right)$ is around $700 \%$; this is plotted in Fig. $3 \mathrm{~b}$ as a dashed line. The data on the left side of the line gives an overestimation in the exponential flux due to a too high value of $k$. In literature overestimation of flux by exponential regression methods has been shown before (Kroon et al., 2008; Pedersen et al., 2001).

Exponential regression has to be firmly constrained with measurements at the start of the closure period to prevent overestimation of the flux. For this dataset we decided not to use the exponential fluxes. In the remainder of this study we only use the results of the linear and quadratic regression methods.

\subsection{Significant non-linearity}

Non-linearity in the chamber data is defined to be significant if $r_{a}^{2}$ is smaller for the linear regression method than for the non-linear regression methods, in this study the quadratic regression method. Overall the linear regression method has a higher $r_{a}^{2}$ than the quadratic regression method, but for $32 \%$ of the data $r_{a}^{2}$ is higher for the quadratic than linear regression. These data are regarded significant non-linear. Apparently, the linearity of chamber data can vary throughout the measurement period.

In Fig. 5 the percentage of data with significant non-linearity is depicted for bins of linear $r^{2}$ (bin width 0.05). A distinction has been made between fluxes smaller and larger than the median flux. In this dataset significant non-linearity is found more often for the larger fluxes (48\%) than for the smaller fluxes (15\%). This is also evident from

\section{Non-linearity in $\mathrm{N}_{2} \mathrm{O}$ chamber data affects annual emissions \\ P. C. Stolk et al.}

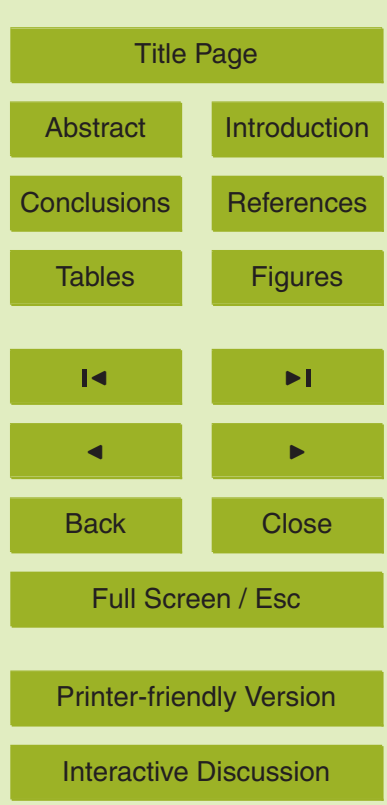


Fig. 3a, where part of the smaller quadratic fluxes is almost equal to the linear fluxes, whereas the larger fluxes show a larger difference.

Comparing this measure for non-linearity with the linear coefficient of determination $r^{2}$, we find no clear relation. Significant non-linearity is found for chamber data 5 with linear $r^{2}>0.5$. As expected, with increasing $r^{2}\left(0.85<r^{2}<1.00\right)$ the percentage data with significant non-linearity decreases, but even $35 \%$ of data with $r^{2}>0.95$ is significantly non-linear. We conclude that the linear $r^{2}$ is not a good measure to check whether linear regression or non-linear regression is better for calculation of the flux from chamber data.

\subsection{Impact of significant non-linearity on daily annual fluxes}

To determine the impact of significant non-linearity on annual fluxes, the linear fluxes were replaced by quadratic fluxes for data with significant non-linearity. Figure $6 a$ and b shows how this affects the instantaneous and daily fluxes, respectively. The larger fluxes (>70 $\mathrm{g} \mathrm{N}_{2} \mathrm{O}-\mathrm{N} \mathrm{ha}^{-1} \mathrm{~d}^{-1}$ ) mainly show non-linear behaviour, resulting in a figure almost equal to that for quadratic fluxes (Fig. 3a). Because of the log-normal distribution of instantaneous fluxes over a day, the larger fluxes are expected to affect the daily means more than the smaller ones. Indeed, the difference between the linear and non-linear daily fluxes increases as compared to the instantaneous fluxes.

In Fig. 7 the annual fluxes, calculated with the linear regression method, the quadratic 20 regression method and the mixture of both is given. The annual fluxes range from 0.6 to $2.9 \mathrm{~kg} \mathrm{~N}_{2} \mathrm{O}-\mathrm{Nha}^{-1}$. These are low compared to other studies on this site (Flechard et al., 2007; Velthof et al., 1996), but this is due to the long periods with missing data that are filled with the median background flux. The relative difference between the linear and mixed annual flux ranges from $21 \%$ to $53 \%$, which is equal to an underestimation in the annual linear flux of $17 \%$ to $35 \%$. It appears that in years with high peak emissions (years 1 and 4) the difference between the linear and mixed annual flux is larger than in years with less high peak emissions (years 2 and 3 ). These values are in good agreement with the result of Anthony et al. (1995), who found a difference between the

BGD

$6,115-141,2009$

Non-linearity in $\mathrm{N}_{2} \mathrm{O}$ chamber data affects annual emissions

P. C. Stolk et al.

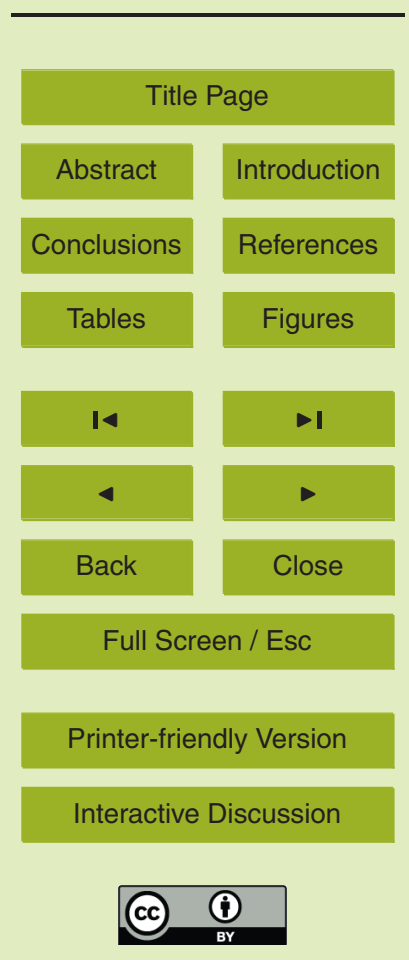


linear and mixed flux of $34 \%$.

\subsection{Causes of non-linearity}

BGD

In this study $32 \%$ of the chamber data shows significant non-linearity, meaning that $68 \%$ of the chamber data is linear. The interesting question is why the concentration changes linearly in some cases and non-linearly in other.

The first main cause for non-linearity is a decreasing diffusion as a result of the increasing concentration in the chamber headspace (Gao and Yates, 1999; Conen and Smith, 2000; Healy et al., 1996; Matthias et al., 1978; Pedersen et al., 2001; Gao and Yates, 1998). This feedback between the concentration in the headspace of the chamber and the soil concentration profile cannot be avoided, but its influence can be minimized by proper chamber height and closure period. Rochette and Eriksen-Hamel (2008) reviewed the improvements in NFT NSS chamber methodology and proposed for chamber height in combination with closure period a value $\geq 40 \mathrm{~cm} \mathrm{~h}^{-1}$ (e.g. chamber height $=20 \mathrm{~cm}$; closure period=30 $\mathrm{min}$ ). However, even then the flux is still slightly affected. Model studies show that for chamber data meeting this criteria linear regression underestimates the real flux by $8 \%$ (Conen and Smith, 2000) or 16\% (Pedersen et al., 2001).

The second main cause for non-linearity in chamber data is leakage, when the $\mathrm{N}_{2} \mathrm{O}$ concentration in the headspace of the chamber is higher than the $\mathrm{N}_{2} \mathrm{O}$ concentration

20 in the free air. There can be leaks in the system itself, but this can be avoided with sufficient care (Conen and Smith, 2000). Lateral diffusion of $\mathrm{N}_{2} \mathrm{O}$ beneath the base of the chamber can also cause leakage. The amount of leakage is related to the depth of the chamber base (Hutchinson and Livingston, 2001). Rochette and EriksenHamel (2008) proposed for the base insertion in combination with the closure period 25 a value $\geq 12 \mathrm{~cm} \mathrm{~h}^{-1}$ (e.g. insertion depth $=6 \mathrm{~cm}$; closure period $=30 \mathrm{~min}$ ). For soils with an air filled porosity of $0.3 \mathrm{~m} \mathrm{~m}^{-1}$ this will give an underestimation of the linear flux $<1 \%$. However, for soils with larger air filled porosities these insertion depths will not prevent leakage through the soil, resulting in larger underestimations (Hutchinson and

\section{Non-linearity in $\mathrm{N}_{2} \mathrm{O}$ chamber data affects annual emissions \\ P. C. Stolk et al.}

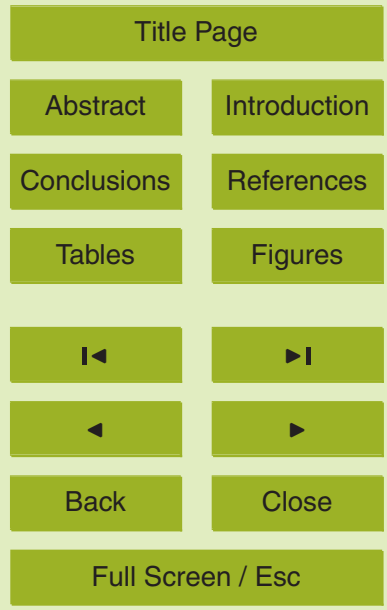

Printer-friendly Version

Interactive Discussion 
Livingston, 2001), even more in windy conditions.

Macropores, such as root and worm holes or shrinkage cracks, provide another way for leakage from the chamber through the soil. Shrinkage cracks are mainly found in clay and peat soils, where the frame of the chamber can act as a natural starting 5 point for cracking. The abundance of macropores is related to the soil conditions and therefore changes over time. For longer measurement periods in particular there is a risk for leakage through macropores. We are not aware of chambers designed to prevent leakage through macropores, or of literature on the influence of macropores on chamber data. We expect fast leakage through macropores and therefore a large 10 underestimation of the linear flux.

The hypothesis we derive from these studies is that even with proper chamber design and deployment (following Rochette and Eriksen-Hamel, 2008) non-linearity in chamber data due to a decreasing diffusion can cause an underestimation in the linear flux up to $16 \%$. Larger underestimations due to more significant non-linearity should be attributed to leakage through the soil, either in dry conditions or through macropores. This hypothesis is hard to verify, because the causes of non-linearity in the chamber data are most often not known. However, a couple of examples support this hypothesis: (Kroon et al., 2008) (underestimation 44\% to 145\%) proved leakage of the chamber by the use of a trace gas; in the study of (Anthony et al., 1995) (underestimation 34\%) leakage through the coarse sandy soil is suggested (Conen and Smith, 2000). In the present study (underestimation $17 \%$ to $35 \%$ ) leakage through cracks might be expected in dry periods, because clayey soils are expected to develop cracks in such periods.

\section{Conclusion}

25 It is clear from the present and other studies that the differences between fluxes calculated with the linear and non-linear regression methods can be large. Yet not all chamber data is significantly non-linear, so the impact of this non-linearity on the an-

\section{BGD}

$6,115-141,2009$

\section{Non-linearity in $\mathrm{N}_{2} \mathrm{O}$ chamber data affects annual emissions}

P. C. Stolk et al.

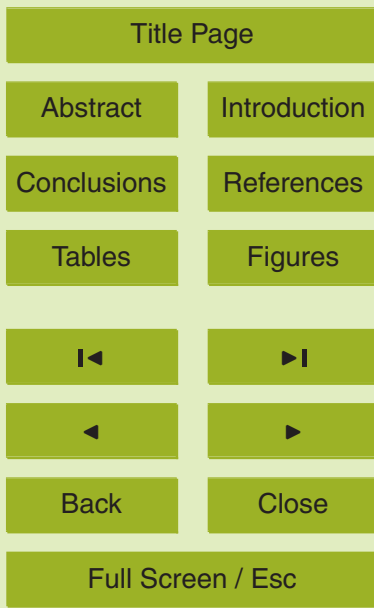

Printer-friendly Version

Interactive Discussion 
nual fluxes is not as large. For this dataset taking significant non-linearity into account, gives a difference in the annual flux up to $53 \%$, what is equal to an underestimation in the linear flux of $35 \%$.

We suggest that underestimations this large $(>16 \%)$ are due to leakage through the 5 soil. More research is needed to unravel the exact causes of non-linearity in chamber data, to find out how macropores influence chamber measurements and how chamber design can be optimized to prevent this. As long as non-linearity cannot be prevented, non-linear regression models should be used for significantly non-linear data. The only constraint we pose on using significant non-linear chamber data is that the concentration change is consistently positive or negative.

Smaller underestimations $(<16 \%)$ in the linear flux can even occur in non-leaking chambers meeting all criteria for proper chamber design and deployment. Significant non-linearity cannot be recognized from the goodness of fit of solely linear regression. Therefore we join with Rochette and Eriksen-Hamel (2008) to recommend more than 3 concentration measurements per closure period and a comparison of the linear and a non-linear regression model on the chamber data. The underestimation might appear small compared to temporal and spatial uncertainties in the $\mathrm{N}_{2} \mathrm{O}$ flux, but it gives a systematic error (bias) in the linear flux, not a random one. This is an undesirable characteristic if national emissions are calculated or models are calibrated using chamber data. Besides, the absolute error is larger for larger fluxes, which have most impact on the annual totals.

We recommend the quadratic regression method as non-linear regression method rather than the exponential regression method. Exponential regression has to be firmly constrained with measurements at the start of the closure period to prevent overestimation of the flux. Although quadratic regression has no theoretical basis other than leakage in general, it is more robust having only few concentration measurements. Moreover, it can never give a worse result than linear regression, because the quadratic term tends to go to zero with increasing linearity.

\section{BGD}

$6,115-141,2009$

\section{Non-linearity in $\mathrm{N}_{2} \mathrm{O}$ chamber data affects annual emissions}

P. C. Stolk et al.

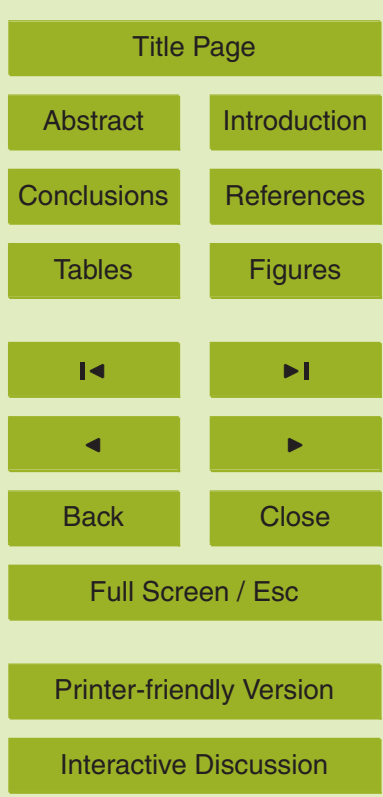


Acknowledgements. This research was carried out in the framework of the Dutch national research program BSIK - Climate changes Spatial Planning and the Climate Change Programme of Wageningen UR. We thank W. C. M. van de Bulk and T. T. Groot from ECN for their part in data collection. We also owe our thanks to G. B. M. Heuvelink and D. M. Kool for their valuable 5 comments on the manuscript.

\section{References}

Anthony, W. H., Hutchinson, G. L., and Livingston, G. P.: Chamber measurement of soilatmosphere gas-exchange - linear vs. diffusion-based flux models, Soil Sci. Soc. Am. J., 59, 1308-1310, 1995.

Breuer, L., Papen, $\mathrm{H}_{\text {., }}$ and Butterbach-Bahl, $\mathrm{K} .: \mathrm{N}_{2} \mathrm{O}$ emission from tropical forest soils of Australia, J. Geophys. Res.-Atmos., 105, 26353-26367, 2000.

Conen, F. and Smith, K. A.: An explanation of linear increases in gas concentration under closed chambers used to measure gas exchange between soil and the atmosphere, Eur. J. Soil Sci., 51, 111-117, 2000.

15 Crutzen, P. J.: Atmospheric chemical processes of the oxides of nitrogen, including nitrous oxide, in: Denitrification, nitrification, and atmospheric nitrous oxide, edited by: Delwiche, C. C., John Wiley \& Sons, New York, 17-44, 1981.

Del Grosso, S. J., Parton, W. J., Mosier, A. R., Ojima, D. S., Kulmala, A. E., and Phongpan, S.: General model for $\mathrm{N}_{2} \mathrm{O}$ and $\mathrm{N}_{2}$ gas emissions from soils due to denitrification, Global Biogeochem. Cy., 14, 1045-1060, 2000.

Denman, K. L., Brasseur, G., Chidthaisong, A., Ciais, P., Cox, P. M., Dickinson, R. E., Hauglustaine, D., Heinze, C., Holland, E., Jacob, D., Lohmann, U., Ramachandran, S., da Silva Dias, P. L., Wofsy, S. C., and Zhang, X.: Couplings between changes in the climate systemm and biochemistry, in: Climate Change 2007: The physical science basis. Contribution of working group I to the Fourth Assessment Report of the Intergovernmental Panel on Climate Change, edited by: Solomon, S., Qin, D., Manning, M., Chen, Z., Marquis, M., Averyt, K. B., Tignor, M., and Miller, H. L., Cambridge University Press, Cambridge, UK and New York, NY, USA, 2007.

Denmead, O. T.: Chamber systems for measuring nitrous oxide emission from soils in the field, Soil Sci. Soc. Am. J., 43, 89-95, 1979.
BGD

$6,115-141,2009$

\section{Non-linearity in $\mathrm{N}_{2} \mathrm{O}$ chamber data affects annual emissions}

P. C. Stolk et al.

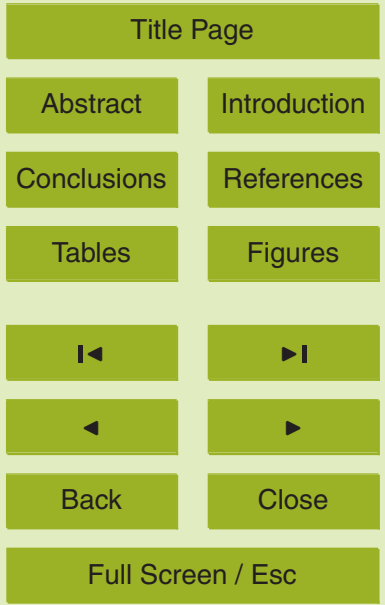

Printer-friendly Version

Interactive Discussion 
Dobbie, K. E. and Smith, K. A.: Nitrous oxide emission factors for agricultural soils in Great Britain: the impact of soil water-filled pore space and other controlling variables, Global Change Biol., 9, 204-218, doi:10.1046/j.1365-2486.2003.00563.x, 2003.

Flechard, C. R., Ambus, P., Skiba, U., Rees, R. M., Hensen, A., van Amstel, A., van den Pol5 van Dasselaar, A., Soussana, J. F., Jones, M., Clifton-Brown, J., Raschi, A., Horvath, L., Neftel, A., Jocher, M., Ammann, C., Leifeld, J., Fuhrer, J., Calanca, P., Thalman, E., Pilegaard, K., Di Marco, C., Campbell, C., Nemitz, E., Hargreaves, K. J., Levy, P. E., Ball, B. C., Jones, S. K., van de Bulk, W. C. M., Groot, T., Blom, M., Domingues, R., Kasper, G., Allard, V., Ceschia, E., Cellier, P., Laville, P., Henault, C., Bizouard, F., Abdalla, M., Williams, M., Baronti, S., Berretti, F., and Grosz, B.: Effects of climate and management intensity on nitrous oxide emissions in grassland systems across Europe, Agr. Ecosyst. Environ., 121, 135-152, 2007.

Gao, F. and Yates, S. R.: Laboratory study of closed and dynamic flux chambers: Experimental results and implications for field application, J. Geophys. Res., 103, 26115-26125, 1998.

15 Gao, F. and Yates, S. R.: Simulation of enclosure-based methods for measuring gas emissions from soil to the atmosphere, J. Geophys. Res.-Atmos., 104, 2211-2211, 1999.

Healy, R. W., Striegl, R. G., Russell, T. F., Hutchinson, G. L., and Livingston, G. P.: Numerical evaluation of static-chamber measurements of soil-atmosphere gas exchange: Identification of physical processes, Soil Sci. Soc. Am. J., 60, 740-747, 1996.

20 Hutchinson, G. L. and Mosier, A. R.: Improved soil cover method for field measurement of nitrous-oxide fluxes, Soil Sci. Soc. Am. J., 45, 311-316, 1981.

Hutchinson, G. L., Livingston, G. P., and Brams, E. A.: Nitric and nitrous oxide evolution from managed subtropical grassland, 10th International symposium on environmental biogeochemistry, 1991, San Francisco, USA, 290-316, 1993.

Hutchinson, G. L. and Livingston, G. P.: Vents and seals in non-steady-state chambers used for measuring gas exchange between soil and the atmosphere, Eur. J. Soil Sci., 52, 675-682, 2001.

IPCC: Emissions Scenarios; Summary for Policymakers, 2000.

IPCC: 2006 IPCC Guidelines for National Greenhouse Gas Inventories, prepared by the National Greenhouse Gas Inventories Programme, IGES, Japan, 2006.

IPCC: Synthesis report. Summary for policymakers, Valencia, Spain, 2007.

Jungkunst, H. F., Freibauer, A., Neufeldt, H., and Bareth, G.: Review article; Nitrous oxide emissions from agricultural land use in Germany - a synthesis of available annual field data,

\section{BGD}

6, 115-141, 2009

\section{Non-linearity in $\mathrm{N}_{2} \mathrm{O}$ chamber data affects annual emissions}

P. C. Stolk et al.

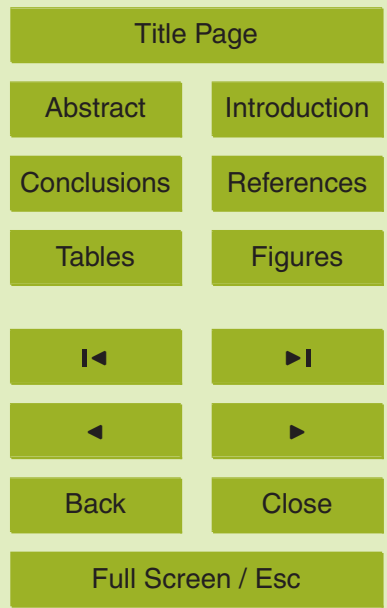

Printer-friendly Version

Interactive Discussion 
J. Plant Nutr. Soil Sc., 169, 341-351, 2006.

Kroon, P. S., Hensen, A., Bulk, W. C. M. v. d., Jongejan, P. A. C., and Vermeulen, A. T.: The importance of reducing the systematic error due to non-linearity in $\mathrm{N}_{2} \mathrm{O}$ flux measurements by static chambers, Nutr. Cycl. Agroecosys., 2008.

5 Kutzbach, L., Schneider, J., Sachs, T., Giebels, M., Nykänen, H., Shurpali, N. J., Martikainen, P. J., Alm, J., and Wilmking, M.: $\mathrm{CO}_{2}$ flux determination by closed-chamber methods can be seriously biased by inappropriate application of linear regression, Biogeosciences, 4, 10051025, 2007,

http://www.biogeosciences.net/4/1005/2007/.

$10 \mathrm{Li}$, C. S., Frolking, S., and Frolking, T. A.: A model of nitrous-oxide evolution from soil driven by rainfall events. 1. Model structure and sensitivity, J. Geophys. Res.-Atmos., 97, 9759-9776, 1992.

Matthias, A. D., Yarger, D. N., and Weinbeck, R. S.: A numerical evaluation of chamber methods for determining gas fluxes, Geophys. Res. Lett., 5, 765-768, 1978.

Matthias, A. D., Blackmer, A. M., and Bremner, J. M.: A simple chamber technique for field measurement of emissions of nitrous oxide from soils, J. Environ. Qual., 9, 251-256, 1980.

de Mello, W. Z. and Hines, M. E.: Application of static and dynamic enclosures for determining dimethyl sulfide and carbonyl sulfide exchange in Sphagnum peatlands: Implications for the magnitude and direction of flux, J. Geophys. Res., 99, 14601-14607, 1994.

20 Neter, J., Kutner, M. H., Nachtsheim, C. J., and Waserman, W.: Applied linear statistical models, 4 edn., 1996.

Parkin, T. B.: Effect of sampling frequency on estimates of cumulative nitrous oxide emissions, J. Environ. Qual., 37, 1390-1395, 2008.

Pedersen, A. R.: Estimating the nitrous oxide emission rate from the soil surface by means of a diffusion model, Scand. J. Stat., 27, 385-403, 2000.

Pedersen, A. R., Petersen, S. O., and Vinther, F. P.: Stochastic diffusion model for estimating trace gas emissions with static chambers, Soil Sci. Soc. Am. J., 65, 49-58, 2001.

Petersen, S. O.: Nitrous oxide emissions from manure and inorganic fertilizers applied to Spring Barley, J. Environ. Qual., 28, 1610-1618, 1999.

30 Pritchard, D. T. and Currie, J. A.: Diffusion of coefficients of carbon dioxide, nitrous oxide, ethylene and ethane in air and their measurement, J. Soil Sci., 33, 175-184, 1982.

Riedo, M., Grub, A., Rosset, M., and Fuhrer, J.: A pasture simulation model for dry matter production, and fluxes of carbon, nitrogen, water and energy, Ecol. Model., 105, 141-183,

BGD

$6,115-141,2009$

\section{Non-linearity in $\mathrm{N}_{2} \mathrm{O}$ chamber data affects annual emissions}

P. C. Stolk et al.

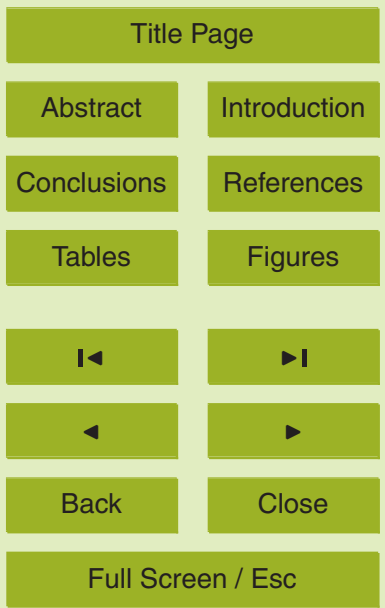

Printer-friendly Version

Interactive Discussion 
1998.

Rochette, P. and Eriksen-Hamel, N. S.: Chamber measurements of soil nitrous oxide flux: Are absolute values reliable?, Soil Sci. Soc. Am. J., 72, 331-342, 2008.

Smith, K. A. and Dobbie, K. E.: The impact of sampling frequency and sampling times on chamber-based measurements of $\mathrm{N}_{2} \mathrm{O}$ emissions from fertilized soils, Global Change Biol., 7, 933-945, 2001.

Soussana, J. F., Allard, V., Pilegaard, K., Ambus, P., Amman, C., Campbell, C., Ceschia, E., Clifton-Brown, J., Czobel, S., Domingues, R., Flechard, C., Fuhrer, J., Hensen, A., Horvath, L., Jones, M., Kasper, G., Martin, C., Nagy, Z., Neftel, A., Raschi, A., Baronti, S., Rees, R. M., Skiba, U., Stefani, P., Manca, G., Sutton, M., Tuba, Z., and Valentini, R.: Full accounting of the greenhouse gas $\left(\mathrm{CO}_{2}, \mathrm{~N}_{2} \mathrm{O}, \mathrm{CH}_{4}\right)$ budget of nine European grassland sites, Agr. Ecosyst. Environ., 121, 121-134, 2007.

Velthof, G. L. and Oenema, O.: Nitrous oxide fluxes from grassland in the Netherlands: I. Statistical analysis of flux-chamber measurements, European J. Soil Sci., 46, 533-540, doi:10.1111/j.1365-2389.1995.tb01349.x, 1995.

Velthof, G. L., Brader, A. B., and Oenema, O.: Seasonal variations in nitrous oxide losses from managed grasslands in The Netherlands, Plant Soil, 181, 263-274, 1996.

Wagner, S. W., Reicosky, D. C., and Alessi, R. S.: Regression models for calculating gas fluxes measured with a closed chamber, Agron. J., 89, 279-284, 1997.

Weitz, A. M., Keller, M., Linder, E., and Crill, P. M.: Spatial and temporal variability of nitrogen oxide and methane fluxes from a fertilized tree plantation in Costa Rica, J. Geophys. Res.Atmos., 104, 30097-30107, 1999.

Yamulki, S. and Jarvis, S. C.: Automated chamber technique for gaseous flux measurements: evaluation of a photoacoustic infrared spectrometer - trace gas analyzer, J. Geophys. Res.,

\section{BGD}

$6,115-141,2009$

\section{Non-linearity in $\mathrm{N}_{2} \mathrm{O}$ chamber data affects annual emissions}

P. C. Stolk et al.

\section{Title Page}

Abstract

Introduction

Conclusions

References

Tables

Figures

14

$\rightarrow$

4

Back

Close

Full Screen / Esc

Printer-friendly Version

Interactive Discussion 


\section{BGD}

$6,115-141,2009$

\section{Non-linearity in $\mathrm{N}_{2} \mathrm{O}$ chamber data affects annual emissions}

P. C. Stolk et al.

Table 1. Results and the goodness of fit of the regressions on the chamber data $a^{a}$.

\begin{tabular}{lllll}
\hline $\begin{array}{l}\text { Regression } \\
\text { method }\end{array}$ & Median flux & Median SSE & Median $r^{2}$ & Median $r_{a}^{2}$ \\
\hline Linear & $1.4^{*}$ & $38.1^{*}$ & $0.88^{*}$ & $0.75^{*}$ \\
Quadratic & $1.9^{* *}$ & $18.0^{* *}$ & $0.94^{*}$ & $0.70^{* *}$ \\
Exponential & $2.1^{* * *}$ & $9.5^{* * *}$ & $0.97^{*}$ & $0.83^{* * *}$ \\
\hline
\end{tabular}

Title Page

Abstract

Introduction

Conclusions

References

Tables

Figures

a Significant differences of the medians among the methods are indicated by different superscripts (Wilcoxon ranksum test, $P<0.05$ ).
14

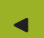

Back

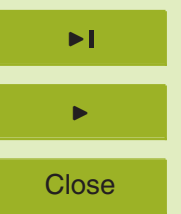

Full Screen / Esc

Printer-friendly Version

Interactive Discussion 
BGD

$6,115-141,2009$

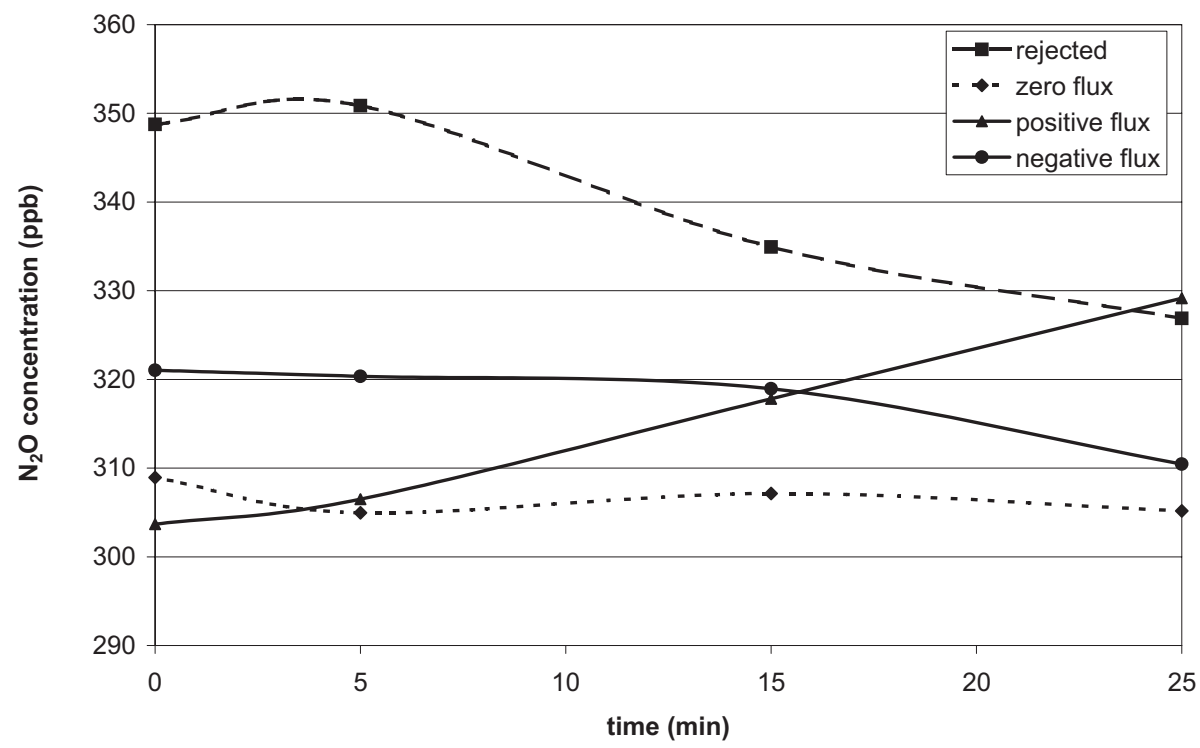

Fig. 1. Typical examples of a rejected, non-consistent flux, a zero flux, a positive flux and a negative flux.

\section{Non-linearity in $\mathrm{N}_{2} \mathrm{O}$ chamber data affects annual emissions}

P. C. Stolk et al.

\section{Title Page}

Abstract Introduction

Conclusions

References

Tables

Figures

14

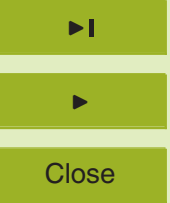

Back

Full Screen / Esc

Printer-friendly Version

Interactive Discussion 
BGD

6, 115-141, 2009

\section{Non-linearity in $\mathrm{N}_{2} \mathrm{O}$ chamber data affects annual emissions}

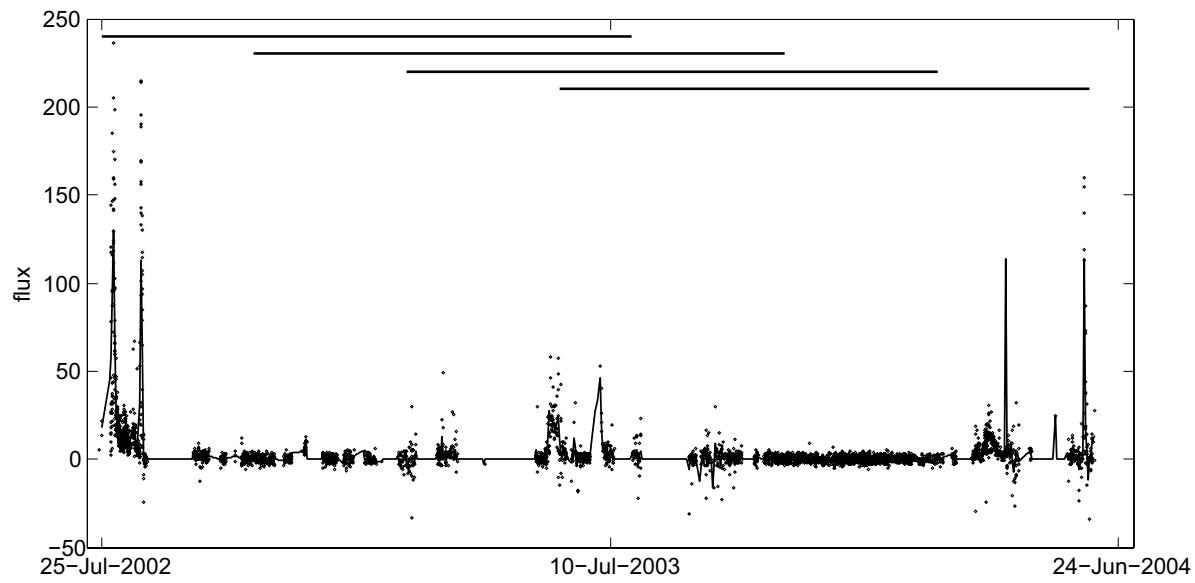

P. C. Stolk et al.

Title Page

Abstract

Introduction

Conclusions

References

Tables

Figures

14

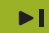

4

Back

Full Screen / Esc

Printer-friendly Version

Interactive Discussion 


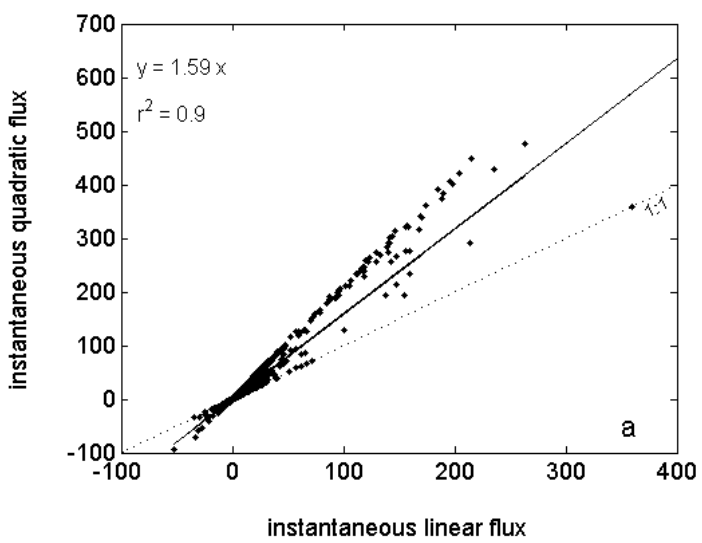

\section{BGD}

\section{6, 115-141, 2009}

\section{Non-linearity in $\mathrm{N}_{2} \mathrm{O}$ chamber data affects annual emissions}

P. C. Stolk et al.

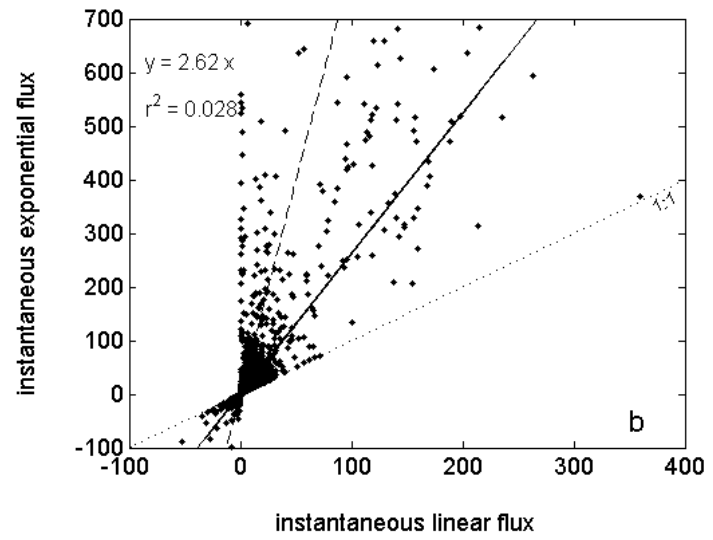

Title Page

Abstract

Introduction

Conclusions

References

Tables

Figures

14

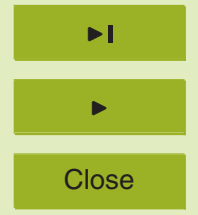

Back

Close

\section{Full Screen / Esc}

Printer-friendly Version

Fig. 3. Comparison of instantaneous linear fluxes with (a) quadratic fluxes and (b) exponential Interactive Discussion lluxes, fluxes in $\mathrm{g} \mathrm{N}_{2} \mathrm{O}-\mathrm{Nha}^{-1} \mathrm{~d}^{-1}$. The solid line is the fitted linear regression line, forced exponential fluxes left of the dashed line are non-reliable. 
BGD

$6,115-141,2009$

\section{Non-linearity in $\mathrm{N}_{2} \mathrm{O}$ chamber data affects annual emissions}

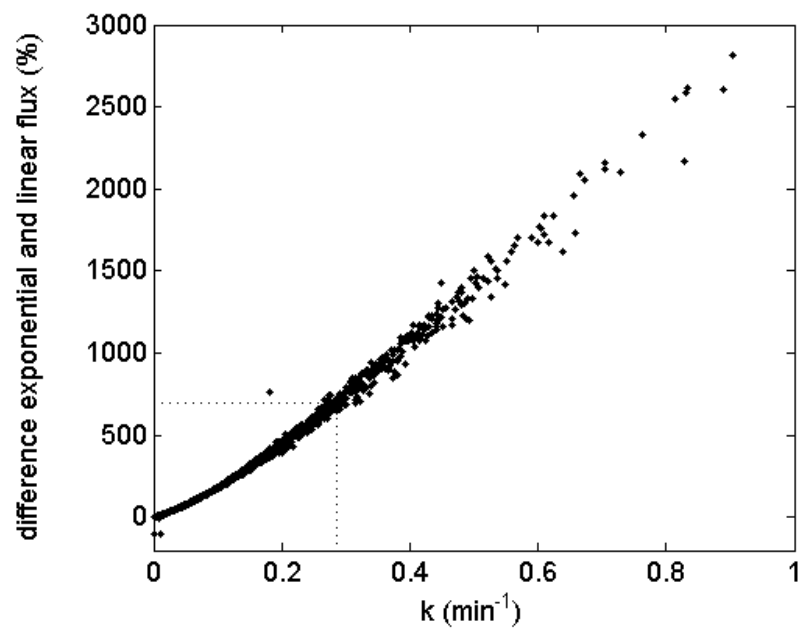

P. C. Stolk et al.

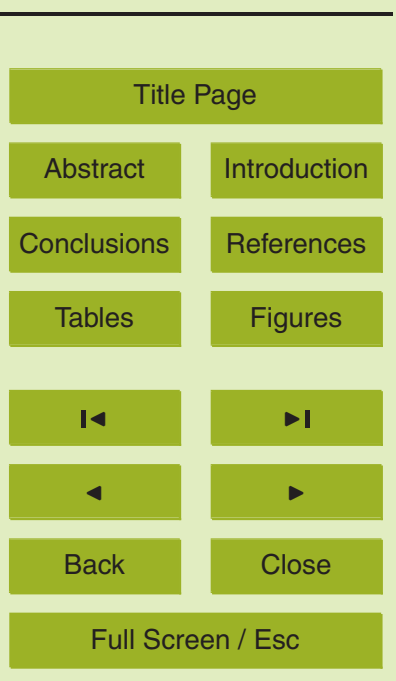

Printer-friendly Version

Interactive Discussion

\section{Full Screen / Esc}

Fig. 4. The results of exponential regression: the rate constant $k$ versus the relative difference between the exponential and linear flux; $2 \%$ of the data lies outside the range of the figure. The dotted lines indicate the physical maximum value for $k$. 
BGD

6, 115-141, 2009

\section{Non-linearity in $\mathrm{N}_{2} \mathrm{O}$ chamber data affects annual emissions}

P. C. Stolk et al.

Title Page

Abstract

Introduction

Conclusions

References

Tables

Figures

14

I

linear $r^{2}$

Fig. 5. Percentage of data with significant non-linearity. Data are binned for $r^{2}$ of the linear regression. The black and white bars represent data with a linear flux larger and smaller than the median, respectively.
4

Back

Close

Full Screen / Esc

Printer-friendly Version

Interactive Discussion 


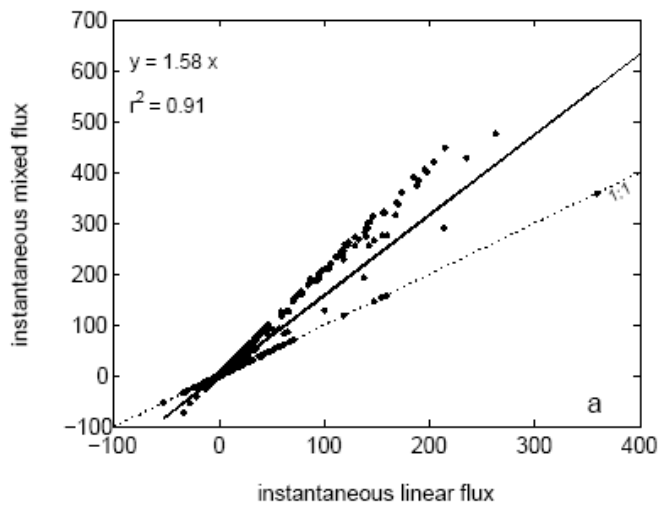

\section{BGD}

$6,115-141,2009$

\section{Non-linearity in $\mathrm{N}_{2} \mathrm{O}$ chamber data affects annual emissions}

P. C. Stolk et al.

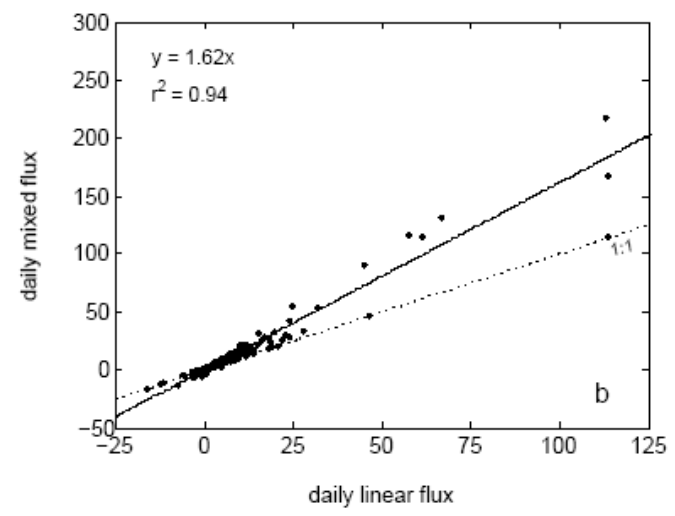

Title Page

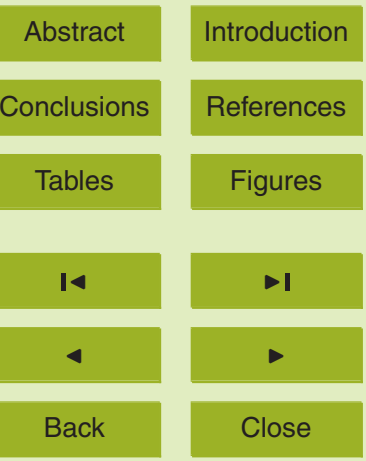

Full Screen / Esc

Fig. 6. Comparison of (a) instantaneous and (b) daily linear fluxes with mixed fluxes; fluxes in $\mathrm{g} \mathrm{N}_{2} \mathrm{O}-\mathrm{Nha}^{-1} \mathrm{~d}^{-1}$. The solid line is the fitted linear regression line, forced through zero, of which the equation and $r^{2}$ are given. The dotted line indicates the line 1:1.

Printer-friendly Version

Interactive Discussion 


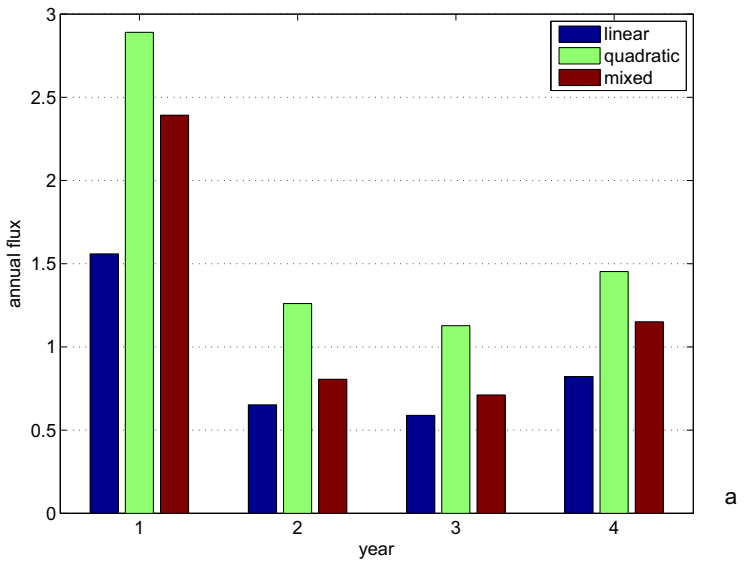

\section{6, 115-141, 2009}

\section{Non-linearity in $\mathrm{N}_{2} \mathrm{O}$ chamber data affects annual emissions}

P. C. Stolk et al.

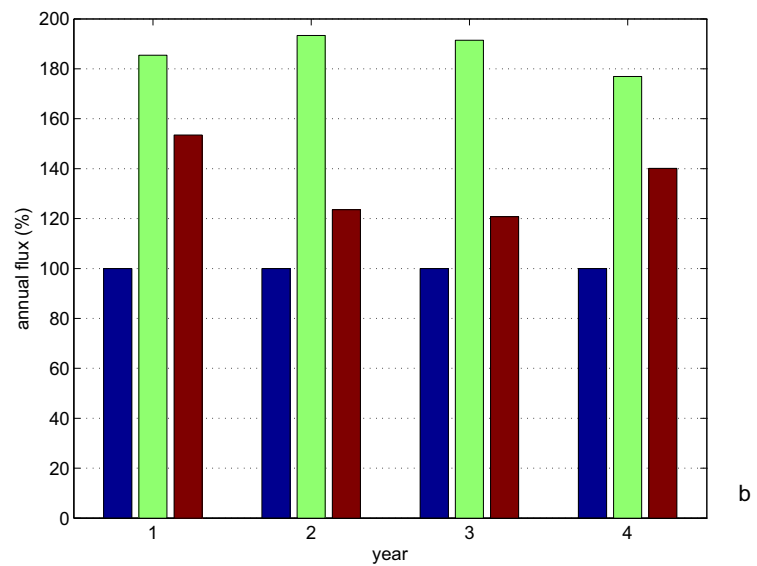

Title Page

Abstract

Introduction

Conclusions

References

Tables

Figures

$\mathbf{I}$

I

4

Back

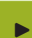

Full Screen / Esc

Printer-friendly Version

Fig. 7. Comparison of annual fluxes calculated with the linear regression method, quadratic regression method and a mixture of both; (a) absolute values of the fluxes, given in $\mathrm{kg} \mathrm{N}_{2} \mathrm{O}-\mathrm{N} \mathrm{ha}^{-1} \mathrm{yr}^{-1}$; (b) annual fluxes relative to the linear annual flux.

Interactive Discussion 